\title{
The "Family" Section in Current Elementary Social Studies Textbooks in China
}

\author{
Weiju Zhao ${ }^{1}$, Zhiping Zhang ${ }^{1}$, Juan Liu $^{2}$ \\ ${ }^{1}$ School of Education Science, Nantong University, Nantong, Jiangsu, China \\ ${ }^{2}$ Beiqiao Central Primary School, Suzhou, Jiangsu, China \\ Correspondence: Weiju Zhao, School of Education Science, Nantong University, Nantong, Jiangsu, China.
}

$\begin{array}{lr}\text { Received: July 18, } 2017 & \text { Accepted: September 4, } 2017 \quad \text { Online Published: September 7, } 2017 \\ \text { doi:10.11114/jets.v5i10.2639 } & \text { URL: https://doi.org/10.11114/jets.v5i10.2639 }\end{array}$

*This research was funded by the Key Project from Chinese National Education Science of the 12th Five-years Plan (DEA120200).

\begin{abstract}
Family is the essential unit of society as well as the pupils' cradle for growing up. It is particularly significant to help pupils understand "family", then form a scientific concept of the family and develop a positive family sentiment. In the current primary school textbooks of "Morality and Life (Society)" (version of the People Education Press) "family" is an important theme. The textbooks embody the basic "student-oriented" idea of the new curriculum concept. And the contents are derived from life which are integrated with other disciplines that shows a sense of comprehensiveness. Yet the textbooks have certain limitations and deficiencies as well. For instance, the contents involving the family types lack variety; some activities introduced lack operability.
\end{abstract}

Keywords: elementary school, People's Education Press, morality and life, family

\section{Introduction}

Sociality is one of the most fundamental qualities of mankind. Family is the earliest holder of the socialization process of mankind. With the growth of children, family lays the foundation for its socialization process and creates its ideological and moral quality (Zhang, 2005). Therefore, it is particularly significant to help pupils understand "family", then form a scientific concept of the family and develop a positive family sentiment.

This article aims to study the "family" section in the "Morality and Life (Society)" PEP textbooks which is significant theoretically and practically in the following aspects: the study of the "family" section in the primary school is the development of the existing ideological and moral education (Liu, 2004). Among the literature of the "family" section in the primary school textbooks of "Morality and Life (Society)", there is a lot of research on the whole set of textbooks yet little research on the "family" section. In addition, there are a majority of research in speculative research and voice of experience yet the research based on specific data analysis is insufficient. Therefore, this study uses the statistical analysis method to study the "family" section in the current primary school "Morality and Life (Society)" textbooks published by the People Education Press.

\section{The "Family" Section}

The current primary school "Morality and Life (Society)" textbooks published by the People Education Press (hereinafter referred to as "PEP") include a total of 152 lessons, of which 9 lessons are about the "family", accounting for $5.92 \%$ of the total textbook. There are 4 lessons in the junior grade among them, namely "My Family", "the Love of Family", "I Have Fun with My Family" and "We Have Grown up". There are 5 lessons in the middle grade, namely "I Love My Family", "the Love of Family", "Read Mom and Dad's Mind”, "A Little Family Account Book" and "Make Grandpa and Grandma Happy". In the junior grade, the "family" lessons are mainly for students to have a basic understanding of the family, to comprehend the family's love for them and learn to appreciate it; in the middle grade, the "family" lessons are mostly to allow students to read the parental loving for them, know how to care for their parents and show filial piety towards their grandparents, and understand that money is hard-earned as well. The main themes involved are: understanding of the family, the love of parents, family responsibility, filial piety towards the 
family and a little family account book, etc. Details are shown in "Table1".

Table1. The "family" in the textbooks

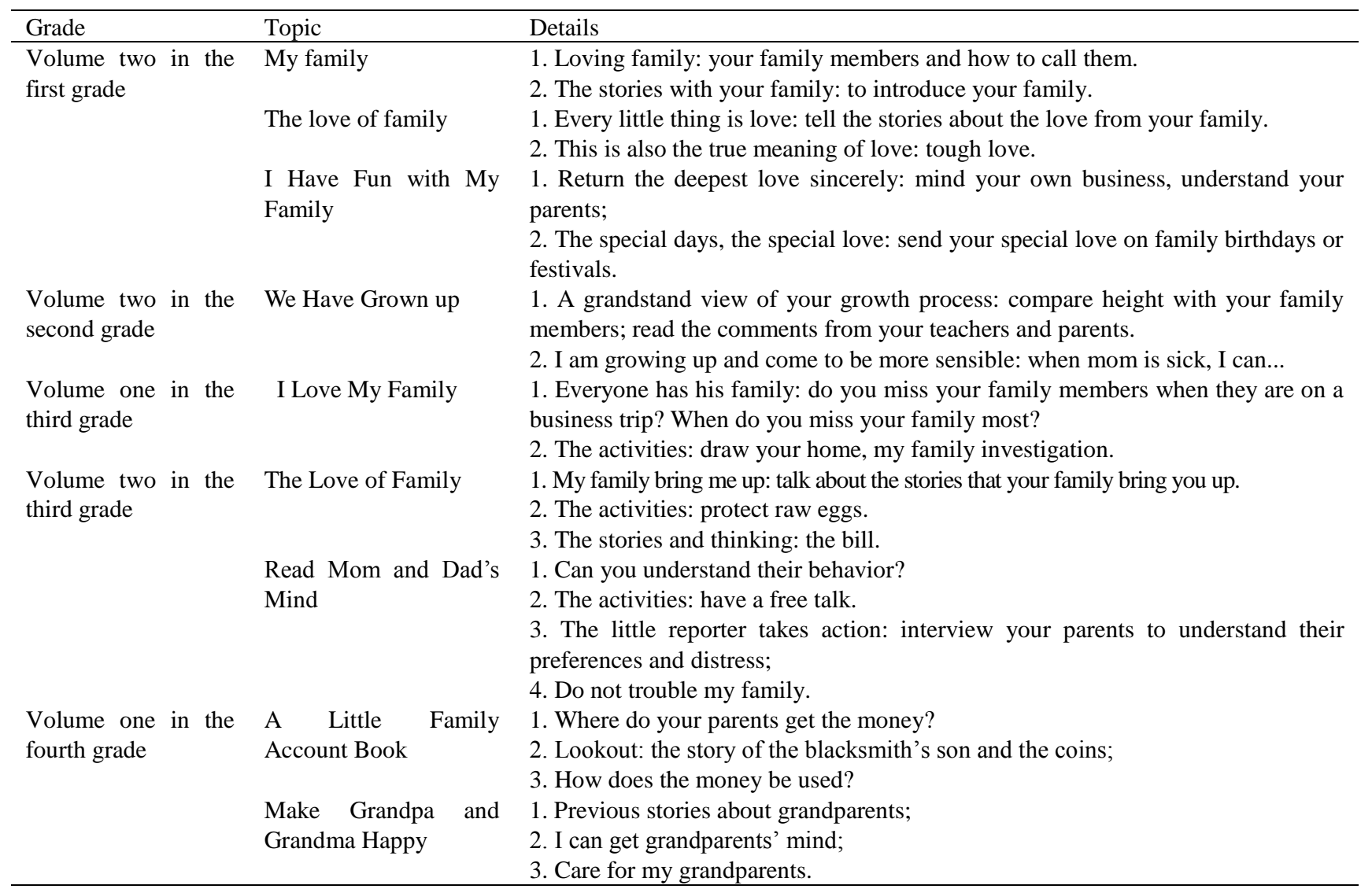

\section{Contents}

As a member of the family, pupils should be taught correctly by their parents, learn to shoulder the duties and responsibilities to their family as well as undertake housework on their own and help their parents solve the difficulties they encountered. Among the literature about the "family" section in the primary school textbooks of "Morality and Life (Society)", there are lot of research on the whole set of textbooks yet little research on the "family" section. For instance: Comparison and Analysis of the Textbook Life Published by Nanyi Press in Taiwan and Morality and Life Published by Jiangsu Education Press---Taking the Unit "Family and I" as Examples written by Li, is aimed the "family" section in Jiangsu Education Edition. Then there are less research about the textbooks published by the People Education Press, but it still could refer to the "family" section in some related research, such as The Comparison and Analysis of Moral and Social Textbooks written by Zhang, M. C. (Zhang, 2012), and the Comparison and Analysis of Moral and Social textbooks in Primary Schools written by Yi, Y. Y. (Yi, 2011). These two literature pointed out the "family" section in People Education Press reflect that the content of the whole textbook gradually increased as well as highlight the deepening of the contents (Zhang, 2004). This change is mainly reflected in the relationship with the family. "I Love My Family" in volume one in the third grade shows the pictures reflecting happy family life to guide students to introduce their own family life and enlighten them to express love and concerns for their families through various forms. Besides, investigating their elders' childhood life can help students to feel changes in family life. "The Love of Family" and "Read Mom and Dad's Mind" in volume two in the third grade, in addition to enlightening students to express love for their families, also lead them to think about the love of their parents hidden behind the praise or anger and understand the different forms of love from parents with their growth. But above all, the love towards their parents is not just understanding their parents, but expands to practical actions, that is, learning to arrange their own life, troubling their parents as little as possible and caring about the family life. It could help pupils learn to love their families, and then love others even their country.

There is a lot of research on the whole set of textbooks yet little research on the "family" section. In addition, there is a majority of research in speculative research and voice of experience yet the research based on specific data analysis is insufficient. Therefore, this study uses the statistical analysis method to study the "family" section in the current primary school "Morality and Life (Society)" textbooks published by the People Education Press. 


\subsection{The Contents Are From Life}

The "Morality and Life (Society)" PEP textbooks revolve around children's life. With the growth of children, their life circle has been expanding all the time, from family to school, then to the community, till in the end to society. The textbook takes the growing life of children as the theme to form several aspects of the teaching contents. The contents of "family" come from life, which takes the real life situation as the breakthrough point. It embodies the theory of practice and the unity of knowledge and practice that can stimulate interest of students (Zhao, Guo, \& Ban, 1995). In "the Family of Love" (Volume two in the first grade), there are a good many scenes in our daily life, such as "My mom does something for me every day...", "My parents always stay with me on the weekend...", "When I was sick..." etc. Students can learn their parents' love for them through these sections. "Read Mom and Dad's Mind" (Volume two in the third grade) contains these sections: " 'Why did you come back so late', father asks angrily", "My mom praises the awful food that I make" etc. To bring these daily life scenes into the textbooks, students can better understand their parents' encouragement and concerns for them through discussions with their peers and teachers' guidance.

\subsection{Difficulty of the Contents Increases with the Development of the Students}

If the topics in the lower grades are to reemerge in the higher grades, the teaching requirements should increase gradually with the growth of grades, which should have a certain logic and ascent instead of simple repetition. In volume two in the first grade, "My Family", "the Love of Family" and "I Have Fun with My Family" mainly help students to understand parents and their love. "I Love My Family" in volume one in the third grade shows the pictures reflecting happy family life to guide students to introduce their own family life and enlighten them to express love and concerns for their families through various forms. Besides, investigating their elders' childhood life can help students to feel changes in family life. "The Love of Family" and "Read Mom and Dad's Mind" in volume two in the third grade, in addition to enlightening students to express love for their families, also lead them to think about the love of their parents hidden behind the praise or anger and understand the different forms of love from parents with their growth (Zhang, 2004). But above all, the love towards their parents is not just understanding their parents, but expands to practical actions, that is, learning to arrange their own life, troubling their parents as little as possible and caring about the family life. "A Little Family Account Book" and "Make Grandpa and Grandma Happy" in volume one in the fourth grade are no longer confined to family affection but extended to family financial management; and no longer limited to the love of their parents but extended to grandparents. The arrangement of the "family" contents in the textbooks is not blind but continuously deepens and increases gradually.

\subsection{The Contents Are Integrated with Other Disciplines, Which Shows a Sense of Comprehensiveness}

The "Morality and Life (Society)" PEP textbooks for primary schools are a comprehensive and multidisciplinary course including culture, economy, geography, history and other fields. Through influences of historical stories and cultural traditions, students can understand themselves, others even the society better and form the right values (Zhang, \& Bai, 2012). For example, "Painting My Family" is related to art that promote the students to understand their family; "My Family investigation" is related to history, in which students' understanding of their family increases through investigating their family's previous experience. "The Bill" is related to economy which shows that it is difficult to support a family and the parents' selfless love for them; and "The Story of the Blacksmith's Son and the Coins" is related to history which allows students to understand that money is not easy to earn and should be cherished.

\subsection{The Contents Involving Family Are Not Broad Enough}

In the "Morality and Life (Society)" PEP textbooks, the contents of "family" are mostly concerned about love and a variety of ways of love, which are more about emotions and values. Although there is a text about the family finance, it is not enough to understand family from it. Some important aspects are missing, for instance, family safety awareness, family table etiquette, the plants and animals in the family. If we are to cultivate students' family values, we should allow students to fully understand every corner of the family, including all of its aspects.

\subsection{The Contents Involving the family Types Lack Variety}

In the "Morality and Life (Society)" PEP textbooks for primary schools, "family" almost describes life in regard to parents and children, in which the picture is more about their extended family. But in real life, there are many divorced families, single parent families and families whose children cannot live with their parents because the parents work far away from home and therefore the children are left behind at home by their parents (Fan, 1998). In volume two in the first grade, "The Love of Family" gives a picture of such left-behind children's family: "My parents work in a faraway place so I live with my grandparents, they will...when they have time". But nothing is mentioned about single-parent families and divorced families. Faced with the various family types today, it is necessary to teach students to understand them. In Volume A of the fifth grades in Current Elementary Social Studies Textbooks in Australia, there is a comprehensive demonstration about the various family types: "There are many different kinds of families. Some 
families have grandparents or other people living with them. Sometimes people from two different families become one family". Teachers guide the pupils to understand and respect the different family types from them, which is conducive to helping students view the family of others correctly and also cultivate respect for and understanding of the family of others (Chen, \& Chen, 2012). The textbooks do not bring the various family types into the contents, however, these students are precisely what we should pay more attention to. Avoiding talking about such topics will not solve the problem but will make matters worse.

\subsection{The Activities Introduced Are Exploratory But Lack Operability}

The new curriculum concept initiates an investigation study, which is a learning style enabling students to discover and gain knowledge from their own practices (Levinson, 2015). There are a variety of activities in the Morality and Life textbooks for primary schools, including "have an investigation", "observation and discovery", "operational practice", "communication and debate", "story and thinking" and "have a game", etc. The textbooks printed by PEP mainly design such activities as "have an investigation", "operational practice" and "story and thinking". The "Family" part in the Morality and Life textbooks for primary school presents the activities in the way of "The little reporter takes action", including "my family investigation" and "interview your parents", etc; the operational practice includes "protect raw eggs"; the story and thinking includes "the bill", "the story of the blacksmith's son and the coins". Activities are an important way for students to understand themselves and their surroundings. The "family" in the current PEP edition of Morality and Life textbooks for primary schools is concerned about the design and presentation of this learning style, which fully embodies the inquiry learning idea of the new curriculum.

In order to reflect the subjectivity of students in the learning process, the PEP textbooks arrange a variety of learning methods, including observation, discussion, communication, investigation, interviews, reports and many other forms. These ways have an irreplaceable role to strengthen the student's personal experience, sentiment and promote students energetically in learning. But do these methods take into account the actual situation of students, such as: students' level of cognition, students' knowledge, teachers' ability, school resources and so on? If these factors are not taken into consideration, the variety of learning methods above would be castles in the air (Bullough, 2011). In "the Love of Family" (Volume two in the third grade), the activity "protecting raw eggs" is relatively impossible to implement. On the one hand, the parents would not allow students to bring raw eggs to school; on the other hand, it would cause students to listen inattentively and chaotic classrooms. In addition, many of these activities devised in the textbooks provide instructions but lack a description of the purpose and requirements, which will lead to certain blindness in the activities of the students. The results of these activities may be: "bustling in class, forgotten after class". Activities look rich and able to arouse the students' interest in learning, but they have deviated from the teaching objectives, thus cannot achieve the teaching effect of this class.

\section{Presentation}

\subsection{Cartoons Have Changed, Which Reflects the Stage of Development}

The cartoons often appearing in the lower grade are about Bunny Bebe. Students in the lower grade are fond of fairy tales and animals so that they seem to enter into a fairy tale kingdom. The cartoons create a pleasant learning environment for students. When they are promoted to the higher grade, Bunny Bebe is replaced by a little boy, which accords with the cognitive and age characteristics of students and can cause students to focus on the contents of learning.

\subsection{Too Many Pictures Are Not Conducive To Reflecting the "Ideology" of the Curriculum}

The outstanding presentation feature of the PEP textbooks is that they are illustrated. The pictures in the textbooks are basically cartoons or pictures from the real life of the children. Students in the lower grades of primary school are more interested in new things. These pictures can not only draw students' attention, but also arouse their interest in learning and their desire to observe. But for the middle and higher grades, the presentation of cartoons at this high frequency seems too childish, which does little good in helping the students to focus on the content and reflect the "ideology" of the curriculum. For the compiling of teaching materials, the most important thing is to grasp the internal relationship between the images and the texts so that they complement each other (Gao, 2001).

\subsection{There Are More Cartoon Pictures than Real Life Pictures}

In the textbooks printed by PEP, there are more cartoon pictures than real life pictures. The cartoon pictures can attract the attention of students, but ignore the effect of the real life pictures, which possess strong appeal and can give students a sense of reality. The students receive the influence of emotions and much educational significance.

\subsection{The Number of Words Is Increasing Each Year}

Pictures are more intuitive, easy-to-understand and simple than the text. But the pictures have a certain degree of 
ambiguity in expression, which is not easy for students to understand the meaning. But on the contrary, the text is more direct and clear so that students are clear at a glance. Reasonable graphic arrangements can make the textbooks vivid, ornamental and readable. In the junior grades, the introduction of each lesson has only one sentence or even without any words, but in the middle grades, the introduction is replaced by a paragraph; and the words in the text are from short sentences to long ones; in the lower grade, the contents of the material are simple and easy-to-understand articles or instructing students to paint; in the middle grades, they become long stories. The length of word description is increasing with the volume, which is consistent with the continuous improvement of children's cognition with academic development.

\subsection{There Are a Lot of Questions throughout the Text, in Which the Words Are Connoted Emotionally}

The main sentence patterns in the textbook are statements, questions, imperative sentences and others, in which a large number of questions are its major feature. Through clearing up, the author has found mainly questions of the following three aspects: first, Bebe's questions are generally related to the theme of this lesson. For example, in "I Have Fun with My Family", Bebe asks "What would you do?" to guide students to be filially pious to their parents with practical actions so that the family is full of laughter; second, the cartoon characters raise questions related to the real life; third, the questions raised in the editor's tone generally appear in the introduction part that is concerned with the overall situation. Statistically, each text generally has 4 to 6 questions which, through exploring them, help students to explore improve their cognitive level, master the process and methods and cultivate emotional attitudes and values. The questions are the important framework that makes up the contents of the textbook (Huang, \& Huo, 2002).

\subsection{The Text Creates a Relaxed Learning Environment}

The language in the text is in accordance with the children' psychological state. Personal pronouns are basically the words in the context of a dialogue, such as "you", "me" and "we". The text is natural and approachable to read so that students are fond of them. And it is conducive to creating a relaxed and happy learning atmosphere. In this kind of environment, it is easy to arouse students' interest in learning and accept the knowledge.

\subsection{The Textbooks Embody the Children's Dominant Position}

The most pronounced pronouns in the textbook are "I" and "we", which is conducive to the fact that students regard themselves as the protagonists of the text, resulting in empathy and personal feelings for the situation and emotions of the characters. What's more, it can contribute students to be influenced by the textbooks. This design principle embodies the basic idea "student-oriented" of the new curriculum concept. (Gu, 2001). The text has changed from "teacher-oriented" to "students-oriented", which is conducive to highlighting the dominant position of students. And the deeper reason is that it is influenced by the theory of student-subject and the quality-oriented education concept.

\section{Conclusion}

The "family" section is close to life and comprehensive in the current primary school "Morality and Life (Society)" PEP textbooks. The contents are consistent with the physical and mental development of pupils, and highlight the theory of student-subject and the quality-oriented education concept (Chen, \& Du, 2012). It can not only teach the pupils to understand and love their families but also contribute to forming a correct family values. In addition, the reasonable presentation of the texts and images in the textbooks is beneficial to creating a relaxing and pleasant learning environment for pupils of all ages. However, the contents involving family are not broad enough. The "family" section is more involved in love, including understanding the love of parents and learning to love their parents. Yet the family education definitely should not be confined to love, but should include many other aspects such as family safety awareness and family table etiquette. What is more, the family types involved are much too single in the textbooks, which is not conducive to helping children learn to maintain a correct view and then offer equality and respect for the families that are different from theirs (Lin, 2004). Additionally, it remains to be studied whether the "family" section could adapt to the different situation of urban and rural households.

\section{References}

Bullough, R. V. (2011). Ethical and Moral Matters in Teaching and Teacher Education. Teaching and Teacher Education, 27(1), 21-28. https://doi.org/10.1016/j.tate.2010.09.007

Chen, G. Q., \& Du, S. Z. (2012). The Reforming of the Moral Education Curriculum for Ten Years: Reflection and Foresight. Course-Teaching Material-Method, 2012(5), 86.

Chen, Z. C., \& Chen, J. L. (2012). To Strengthen the Teaching Management of Moral Course then Improve the Teaching Effect of it--The Practice and Exploration of Moral Education in Primary Schools. Education and Teaching Forum, 2012(40), 45-46.

Fan, Y. Z. (1998). Materials Design and Development. Beijing: Higher Education Press. 
Gao, L. B. (2001). The Analysis and Evaluation of the Model and level of teaching material. Curriculum Teaching materials Teaching method, 2001(3).

Gu, M. Y. (2001). The Century Retrospect of Curriculum Reform. Education Research, 2001(7).

Huang, X. H., \& Huo, B. K. (2002). Looking for the basis of curriculum theory and textbook design. Beijing: People's Education Press.

Levinson, M. (2015). Moral injury and the ethics of educational injustice. Harvard Educational Review, 85(2), 203-228. https://doi.org/10.17763/0017-8055.85.2.203

Lin, Q. (2004). The Research on the Experiment of Moral and Life Curriculum. Shanghai: Central China Normal University.

Liu, S. X. (2004). A Comparative Study of Textbooks on Moral and Life in Primary Schools. Shandong: Shandong Normal University.

Wang, G. (2006). The Present Situation and Development of Ideological and Moral Curriculum Reform. Gansu: Northwest Normal University.

Yi, Y. Y. (2011). The Comparison and Analysis of Moral and Social Textbooks in Primary Schools. Shandong: Shandong Normal University.

Zhang, E. J., \& Bai, G. Q. (2012). The Teaching Should Pay Attention to the Combination with Students' Life in Primary Schools. Education for Chinese After-school, 2012(32), 121.

Zhang, M. C. (2004). The Research of Moral and Life (Social) Curriculum and Teaching. Jinan: Shandong Pictorial Publisher House.

Zhang, M. C. (2004). The Research of Moral and Social Studies Standards. Shandong: Shandong Education Press.

Zhang, M. C. (2005). Social Science and Education in China in the 21st Century. Shandong: Taishan Publishing House.

Zhang, M. C. (2012). The Comparison and Analysis of Moral and Social Textbooks. Educational Science Research, 070060-10.

Zhao, C. F., Guo, Q. J., \& Ban, H. (1995). The History of Chinese primary school ideological and moral teaching. Jinan: Shandong Education Press.

\section{Copyrights}

Copyright for this article is retained by the author(s), with first publication rights granted to the journal.

This is an open-access article distributed under the terms and conditions of the Creative Commons Attribution license which permits unrestricted use, distribution, and reproduction in any medium, provided the original work is properly cited. 